\title{
NOTES ON RACCOONS \\ FROM EDAM, SASKATCHEWAN
}

\author{
MURIEL CARLSON, 406 Spruce Drive, Saskatoon, Saskatchewan. S7N 2N4
}

Raccoons are nocturnal animals, and, perhaps because of this, their tracks are more often encountered than the actual animal. In fact, many sightings are actually records of road kills. A recent sighting at Edam became a minor event when Tom and Marg Terpstra discovered Raccoons. Tom described the encounter:

"During the night of 1 October 1990 , we were awakened by an infernal racket caused by our dogs outside our window. They were barking at something in or near the spruce tree beside the window. We presumed that they had treed a squirrel, or encountered a skunk, and attempted to go back to sleep."

"It was cold and windy, but about $0700 \mathrm{~h}$, I finally decided to check outside. I was surprised to find two Raccoons in our maple tree in the front of the house. Our dogs had treed them during the night, and they had escaped across the roof to the other tree."

"The two Raccoons stayed in the maple tree all day, despite a continuous stream of curious residents who came by to see them, Some people brought cameras, and one family made a short home video of them. Throughout most of the day, the two animals sat near each other on the same branch, but as the day became colder and windier, one crawled up beside the other and snuggled up for comfort. They were very affectionate and one would stroke the other's back. By $2200 \mathrm{~h}$, they had separated, and by $2300 \mathrm{~h}$, they were both gone. The following day, a single animal was reported just west of town where the grid road crosses the Turtlelake River."

"On November 18, we were returning home on the grid road east of Edam at $1750 \mathrm{~h}$ and saw a pair of Raccoons scampering in the snow near a clump of willows beside a roadside slough. They were obviously enjoying themselves. That was the last sighting."

Edam is located about $70 \mathrm{~km}$ northwest of North Battleford, just one $\mathrm{km}$ east of the meandering Turtlelake River, and about $16 \mathrm{~km}$ east of the North Saskatchewan River. There are no published Raccoon records from this area, although Sheila Lamont, former Blue Jay editor, informs me that she saw Raccoon tracks on Pine Island a long time ago. Pine Island is $20 \mathrm{~km}$ west of Edam, in the North Saskatchewan River. As well, a farmer near Vawn, southeast of Edam, claimed that Raccoons were bothering his chickens last year and causing some losses, so he destroyed three of them.

Raccoons are known to like attics and granaries or old buildings. Ray Puddicombe, a retired Conservation Officer with Saskatchewan Parks and Renewable Resources, explained that they also 


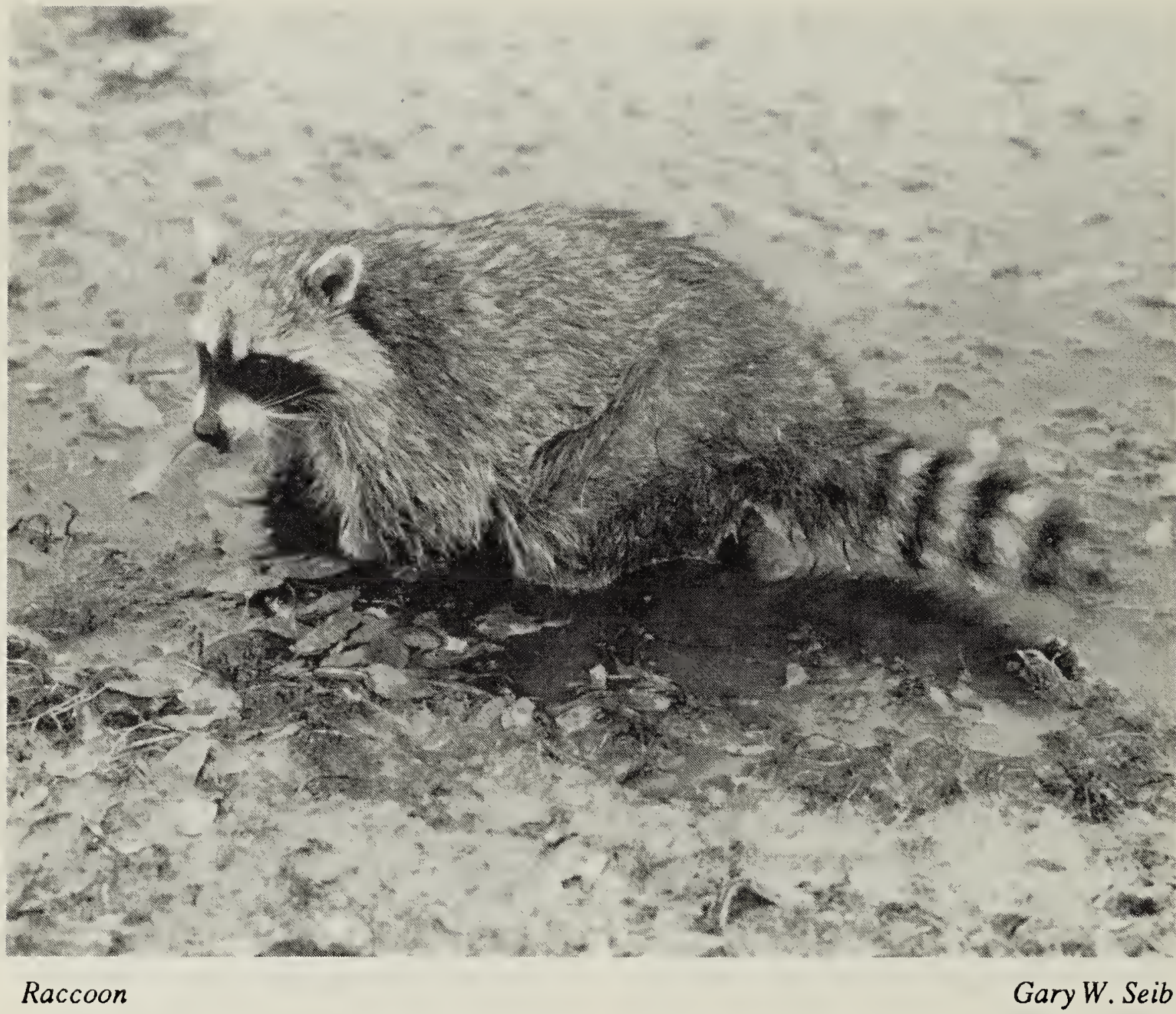

like to pry off old shingles to get at flies and insects beneath them. Such action usually renders the buildings unusable in a short time, so farmers show little affection toward them. Puddicombe also stated that Raccoons were reported as far north as Ile-a-la-Crosse 25 years ago. Raccoons are also believed to be responsible for predation of bird nests. This was reported by Dale Hjertaas during a survey of nests of Great Blue Herons in the Qu'Appelle Valley in $1981{ }^{4}$

A search of Saskatchewan published recorded sightings in the Blue Jay has produced further information about these interesting but often maligned creatures. Raccoons (Procyon lotor) are carnivores and members of the family Procyonidae. They are medium sized, fairly chubby mammals with long fur. They have dark coloured rings on their bushy tails, narrow snouts and a distinct dark mask about the eyes. They are nocturnal, or night feeders, and are believed to sometimes wash their food by holding it with their front paws and rinsing it in a stream. Their diet usually consists of insects, mollusks, frogs, shellfish, eggs and birds. If they are present around water, their tracks are distinctive, the prints of their five prominent toes on each foot appearing to resemble tiny hands rather than padded feet, as the first digit is shorter than the others, similar to our thumbs.

W.H. Beck indicated that the known range of Raccoons in 1958 was mostly in extreme southern Saskatchewan, where only a handful of locations had been reported (Estevan, Regina, Carlyle, Disley, Moose Mountain, etc.), all locations that are reasonably near water. ${ }^{1} \mathrm{He}$ noted, however, that one sighting had been made near Meadow Lake, which is 
about $150 \mathrm{~km}$ north of Edam.

Harris, in 1971, reported several more northerly sightings than Beck, with locations around Raymore, Semans, and Saskatoon. ${ }^{3}$ The annual Christmas Mammal Count compiled by him for Blue Jay shows that Raccoons have been reported ten times. They were recorded at Assiniboia (1981, 1984, 1987), Round Lake (1976, 1985), Indian Head (1978) and Regina $(1979,1980)$.

Houston and Houston give a more detailed history of the Raccoons as well as their historical commercial fur values. ${ }^{5}$ They refer to many more recent sightings that show an extension of territory much further north, with sightings from Mullinger (1968), Northside (1969, 1970) and Christopher Lake (1969, 1970, 1972).

In 1983, Victor Friesen provided additional information from his own sightings near Rosthern and Blaine Lake, both road kills. ${ }^{2}$ He also noted an early sighting by Krivda near Squaw Rapids in 1950 .

On 2 February 1991, the author was part of a group of naturalists who journeyed to the Candle Lake area to search for Hawk Owls. While viewing one with our spotting scopes, I noticed fresh tracks of what I believe to be a Raccoon, in the snow at my feet. I pointed them out to Menno Nickel who was closest at hand. Further discussion with Ray Puddicombe revealed that Raccoons, while overwintering in a hibernating state, do not completely sleep throughout the cold weather. They occasionally venture out during mild spells, much like Red Squirrels do in the northem forests.

This indicates that these small animals have indeed invaded the parkland/boreal interface, and members would be on the lookout for evidence of them. Further information about the habits and history of the Raccoon is available free from Canadian Wildlife Service, 115 Perimeter Road, Saskatoon, Saskatchewan, S7N 0W0.

1. BECK, W.H. 1958. A guide to Saskatchewan mammals. Sask. Nat. Hist. Soc. Publ. No. 1.

2. FRIESEN, VICTOR C. 1983. Furthering Saskatchewan Raccoon records. Blue Jay $41: 223$

3. HARRIS, WAYNE C. 1971. Some recent Saskatchewan Raccoon records. Blue Jay $24: 214$

4. HJERTAAS, DALE. 1982. Great Blue Heron and Raccoons at Nicole Flats. Blue Jay 40:37-41.

5. HOUSTON, C. STUART, and MARY I. HOUSTON. 1973. A history of Raccoon records in Saskatchewan. Blue Jay 31:103-104.

A sacred place is one where the Earth's voice can be heard more clearly. Go to these places and listen. Once you've heard her, she can reach you anywhere.

F. Lehrman. 1988. The Sacred Landscape. Celestial Arts, Berkeley, CA. 